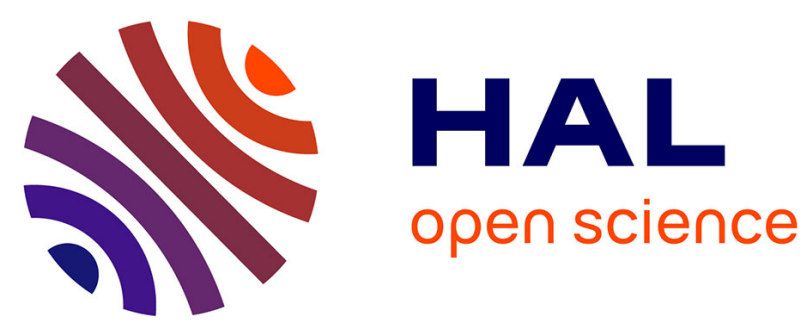

\title{
Novel hydroquinone-alumina composites stabilizing a guest-free clathrate structure: applications in gas processing
}

Romuald Coupan, Peter Moonen, Christophe Dicharry, Frédéric Plantier, Joseph Diaz, Eve Péré, Abdel Khoukh, Fabrice Guerton, Pascale Sénéchal, Cédric Charvillat, et al.

\section{To cite this version:}

Romuald Coupan, Peter Moonen, Christophe Dicharry, Frédéric Plantier, Joseph Diaz, et al.. Novel hydroquinone-alumina composites stabilizing a guest-free clathrate structure: applications in gas processing. ACS Applied Materials \& Interfaces, 2020, 12 (30), pp.34137-34147. 10.1021/acsami.0c06187 . hal-02910839

\section{HAL Id: hal-02910839 \\ https://hal.science/hal-02910839}

Submitted on 20 Nov 2020

HAL is a multi-disciplinary open access archive for the deposit and dissemination of scientific research documents, whether they are published or not. The documents may come from teaching and research institutions in France or abroad, or from public or private research centers.
L'archive ouverte pluridisciplinaire HAL, est destinée au dépôt et à la diffusion de documents scientifiques de niveau recherche, publiés ou non, émanant des établissements d'enseignement et de recherche français ou étrangers, des laboratoires publics ou privés. 


\section{Open Archive Toulouse Archive Ouverte}

OATAO is an open access repository that collects the work of Toulouse researchers and makes it freely available over the web where possible

This is a publisher's version published in: https://oatao.univ-toulouse.fr/26905

\section{Official URL:}

https://doi.org/10.1021/acsami.0c06187

\section{To cite this version:}

Coupan, Romuald and Moonen, Peter and Dicharry, Christophe and Plantier, Frédéric and Diaz, Joseph and Péré, Eve and Khoukh, Abdel and Guerton,

Fabrice and Sénéchal, Pascale and Charvillat, Cédric $\rightleftharpoons$ and Solan, Marie-Line de כ and Torré, Jean-Philippe stabilizing a guest-free clathrate structure: applications in gas processing. (2020) ACS Applied Materials and Interfaces, 12 (30). 34137-34147. ISSN 1944-8244.

Any correspondence concerning this service should be sent to the repository administrator: tech-oatao@listes-diff.inp-toulouse.fr 


\section{Novel Hydroquinone-Alumina Composites Stabilizing a Guest-Free Clathrate Structure: Applications in Gas Processing}

Romuald Coupan, Peter Moonen, Christophe Dicharry, Frédéric Plantier, Joseph Diaz, Eve Péré, Abdel Khoukh, Fabrice Guerton, Pascale Sénéchal, Cédric Charvillat, Marie-Line De Solan, and Jean-Philippe Torré*

Cite This: ACS Appl. Mater. Interfaces 2020, 12, 34137-34147

Read Online

\section{ACCESS \\ Wll Metrics \& More \\ Article Recommendations \\ Supporting Information}

ABSTRACT: Organic clathrates formed by hydroquinone (HQ) and gases such as $\mathrm{CO}_{2}$ and $\mathrm{CH}_{4}$ are solid supramolecular hostguest compounds in which the gaseous guest molecules are encaged in a host framework of HQ molecules. Not only are these inclusion compounds fascinating scientific curiosities but they can also be used in practical applications such as gas separation. However, the development and future use of clathrate-based processes will largely depend on the effectiveness of the reactive materials used. These materials should enable fast and selective enclathration and have a large gas storage capacity. This article discusses the properties and performance of a new composite material able to form gas clathrates with hydroquinone (HQ)

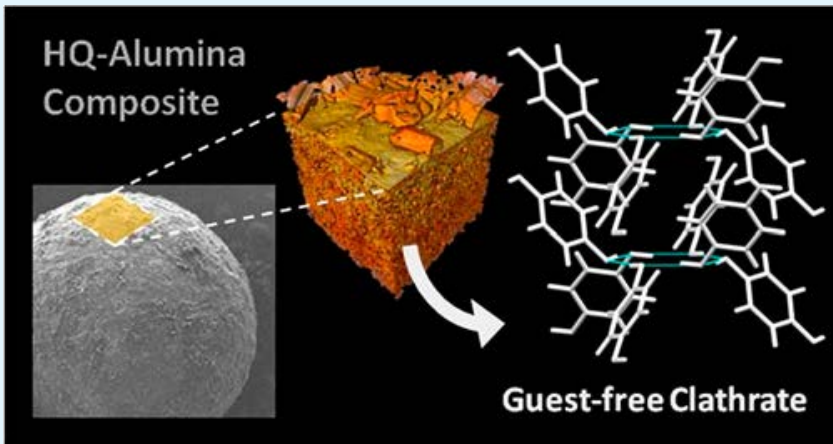
deposited on alumina particles. Apart from the general characterization of the HQ-alumina composite, one of the most remarkable observations is the unexpected formation of a guest-free clathrate structure with long-term stability ( $>2$ years) inside the composite. Interestingly enough, in addition to a slight improvement in the enclathration kinetics of pure $\mathrm{CO}_{2}$ compared to powdered $\mathrm{HQ}$ preferential capture of $\mathrm{CO}_{2}$ molecules is observed when the HQalumina composite is exposed to an equimolar $\mathrm{CO}_{2} / \mathrm{CH}_{4}$ gas mixture. In terms of gas capture selectivity toward $\mathrm{CO}_{2}$, the performance of this new composite exceeds that of pure HQ and HQ-silica composites developed in a previous study, opening up new opportunities for the design and use of these novel materials for gas separation.

KEYWORDS: gas clathrates, hydroquinone, composite material, gas separation, $\mathrm{CO}_{2}$ capture and storage

\section{INTRODUCTION}

Clathrates are inclusion compounds in which guest molecules are trapped in cavities (cages or channels) formed by a lattice of host molecules. ${ }^{1,2}$ Clathrate hydrates (generally known as gas hydrates), which are icelike crystals formed by a network of water molecules encaging small gaseous species ${ }^{3}$ are the most commonly studied. By contrast, organic gas clathrates-in which the host lattices are composed of organic molecules such as hydroxyaromatic compounds ${ }^{1}$ - have been much less investigated. Besides their ability to fascinate scientists for over a century, these organic inclusion compounds, particularly those formed with hydroquinone (HQ), appear to be promising materials for practical applications such as hydrogen storage, ${ }^{4}$ gas separation by selective enclathration, ${ }^{5,6}$ and sequestration of dangerous substances.

The stable structure of HQ under ambient conditions $(\alpha$ form) can be converted, in certain conditions, into HQ clathrates $(\beta$-form $)$ by encaging a variety of suitable guest species such as methanol, acetonitrile, sulfur dioxide, argon, krypton, xenon, and others. ${ }^{2}$ A typical HQ clathrate cavity, showing $12 \mathrm{HQ}$ molecules surrounding a spherical guest, is illustrated in Figure 1. Such cavities are composed of two interpenetrating (but not interconnected) networks of six HQ molecules, linked together by a characteristic planar hexagonal ring of hydrogen bonds, delimiting the top and at the bottom of the cage (see Figure 1).

One of the notable and puzzling features of clathrates is the fact that a guest-free structure (i.e., a clathrate-like structure without any guests present in the cavities) can be formed in certain conditions. ${ }^{8-11}$ Although it is generally admitted that the stability of a clathrate implies the presence of guest molecules in the host framework, evidence of the existence of guest-free structures (i.e., "empty clathrates") has been already reported several times in the literature. In the 1950 s, the

Received: April 3, 2020

Accepted: July 7, 2020

Published: July 7, 2020 

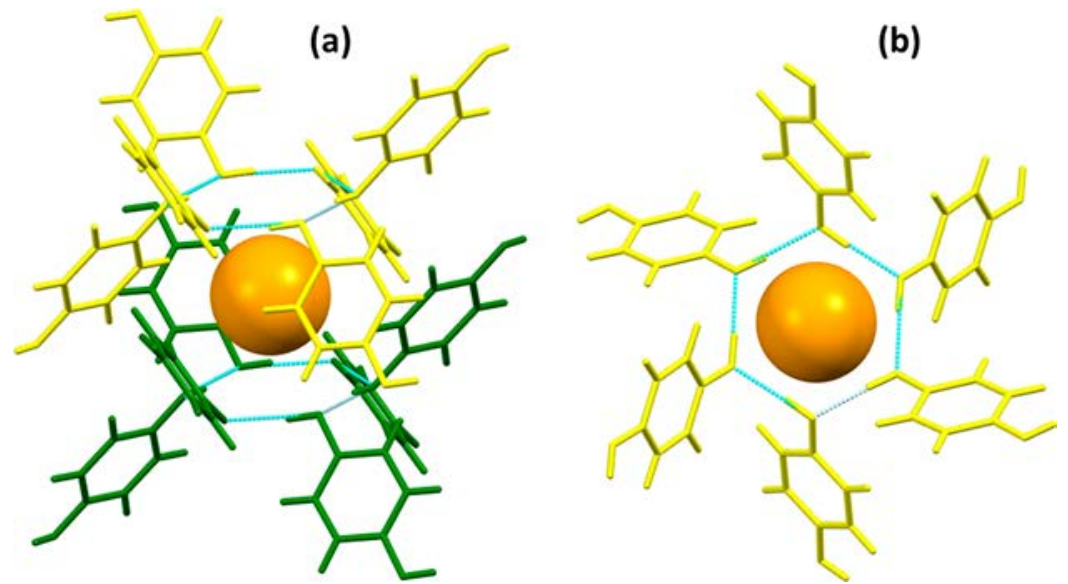

Figure 1. General views of a typical HQ-clathrate cavity. The $12 \mathrm{HQ}$ molecules forming the cage are colored in yellow (six for the top network) and green (six for the bottom network). The orange sphere is the guest molecule. The hydrogen bonds forming the two hexagonal rings at the top and bottom of the cavity are represented in light blue. (a) 3D view; (b) view down the crystallographic $c$-axis.

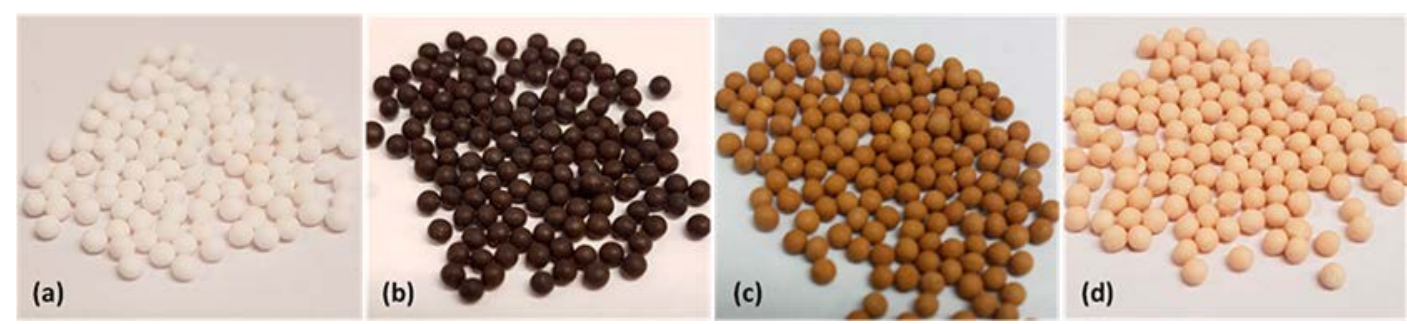

Figure 2. Pictures of (a) the native alumina particles and $(b-d)$ the HQ-alumina composites obtained after drying, using an impregnation solution with (b) no additive, (c) $\mathrm{Na}_{2} \mathrm{SO}_{3}$, and (d) $\mathrm{H}_{2} \mathrm{SO}_{4}$.

phenomenon was reported by Evans and Richards, who prepared HQ clathrates without any enclosed gases by cooling a warm HQ alcoholic solution seeded with an argon HQ clathrate crystal. ${ }^{8}$ Guest-free clathrate structures can be also obtained by progressive heating of HQ gas clathrates until the full release of their guest molecules (e.g., $\mathrm{CO}_{2}$ and $\mathrm{Xe}$ ). ${ }^{9,10}$ Indeed, even with gas hydrates, in which the challenge to obtain a guest-free structure is an incredibly difficult task, an "empty hydrate" (analogous to ice XVI) was identified after 5 days of continuous pumping on small particles of neon hydrate. $^{11}$

It is interesting to note that hydroquinone (HQ) can form gas clathrates directly by gas-solid reactions ${ }^{12}$ over a wide range of temperatures and at a moderate pressure (a few $\mathrm{MPa})^{13}$ in the presence of small gaseous molecules such as $\mathrm{CO}_{2}$ and $\mathrm{CH}_{4} \cdot{ }^{12-14}$ When an equimolar $\mathrm{CO}_{2} / \mathrm{CH}_{4}$ gas mixture is put in contact with either native $\mathrm{HQ}$ or guest-free $\mathrm{HQ}$ clathrates, the $\mathrm{CO}_{2}$ can be selectively captured, the latter form being the more selective. ${ }^{10,15}$ Indeed, the presence of such a structure in an HQ clathrate-based gas separation process is one of the keys to greatly enhancing the selective enclathration toward one of the components in the gas mixture. In addition, the enclathration kinetics can be significantly enhanced by optimizing the gas-solid contact area: the larger the area, the faster the kinetics. ${ }^{16,17}$ In one of the authors' previous studies, HQ-silica composite materials composed of porous silica particles impregnated with $\mathrm{HQ}$ were prepared and tested with pure $\mathrm{CO}_{2}$ and $\mathrm{CH}_{4} / \mathrm{CO}_{2}$ mixtures. This material exhibited faster gas capture kinetics than native $\mathrm{HQ} .{ }^{17}$ However, this type of silica support is not suited to industrial applications, mainly due to its small particle size (500 $\mu \mathrm{m}$ at the most). To overcome this problem, researchers have identified industrial porous alumina particles (with a diameter of 1 to $3 \mathrm{~mm}$ ) as a potential alternative support for impregnation.

The present study therefore addresses the preparation, characterization, and evaluation (in terms of gas capture kinetics, separation selectivity, and gas storage capacity) of these HQ-alumina composite materials in the presence of pure $\mathrm{CO}_{2}$ and an equimolar $\mathrm{CO}_{2} / \mathrm{CH}_{4}$ gas mixture.

\section{EXPERIMENTAL SECTION}

2.1. Materials. The porous supports used (see Figure 2a) are spherical activated alumina particles of $1700-3000 \mu \mathrm{m}$ provided by Axens. HQ with a purity of $99.5 \mathrm{~mol} \%$ is provided by Acros Organics. The gases used for the experiments (helium, $\mathrm{CO}_{2}$, and an equimolar $\mathrm{CO}_{2} / \mathrm{CH}_{4}$ mixture) are purchased from Linde Gas SA and have a minimum mole fraction purity of $99.995 \%$. The solvent used for the impregnation experiments is absolute ethanol (purity greater than 99 mol \%). Sulfuric acid (purity greater than $99 \mathrm{~mol} \%$ ) is used as a $\mathrm{pH}$ regulator for the impregnation solution. Anhydrous sodium sulfite (analytical reagent grade), used as an additive in the impregnation solution during preliminary tests, is provided by Fisher Scientific.

2.2. Apparatuses and Methods. Impregnation Process. The HQ is deposited on alumina supports through wet impregnation. ${ }^{17}$ In short, after a $24 \mathrm{~h}$ thermal pretreatment (i.e., drying) of the alumina supports at $423 \mathrm{~K}$ in a muffle furnace, the alumina particles are immersed in the impregnation solution-HQ-saturated ethanol, acidified to $\mathrm{pH} \sim 3-4$ by a small amount (a few drops) of sulfuric acid-at $308 \mathrm{~K}$ for another $24 \mathrm{~h}$. The impregnated particles are then filtered and placed in the oven to dry at $308 \mathrm{~K}$ for $24 \mathrm{~h}$ in ambient conditions (air).

As shown in Figure 2b, we noticed that if the impregnation solution is not acidified, black particles are obtained after drying. We performed a test with these black particles in contact with pure $\mathrm{CO}_{2}$ (at $3.0 \mathrm{MPa}$ and $323 \mathrm{~K}$ ), measuring only the adsorption on the 

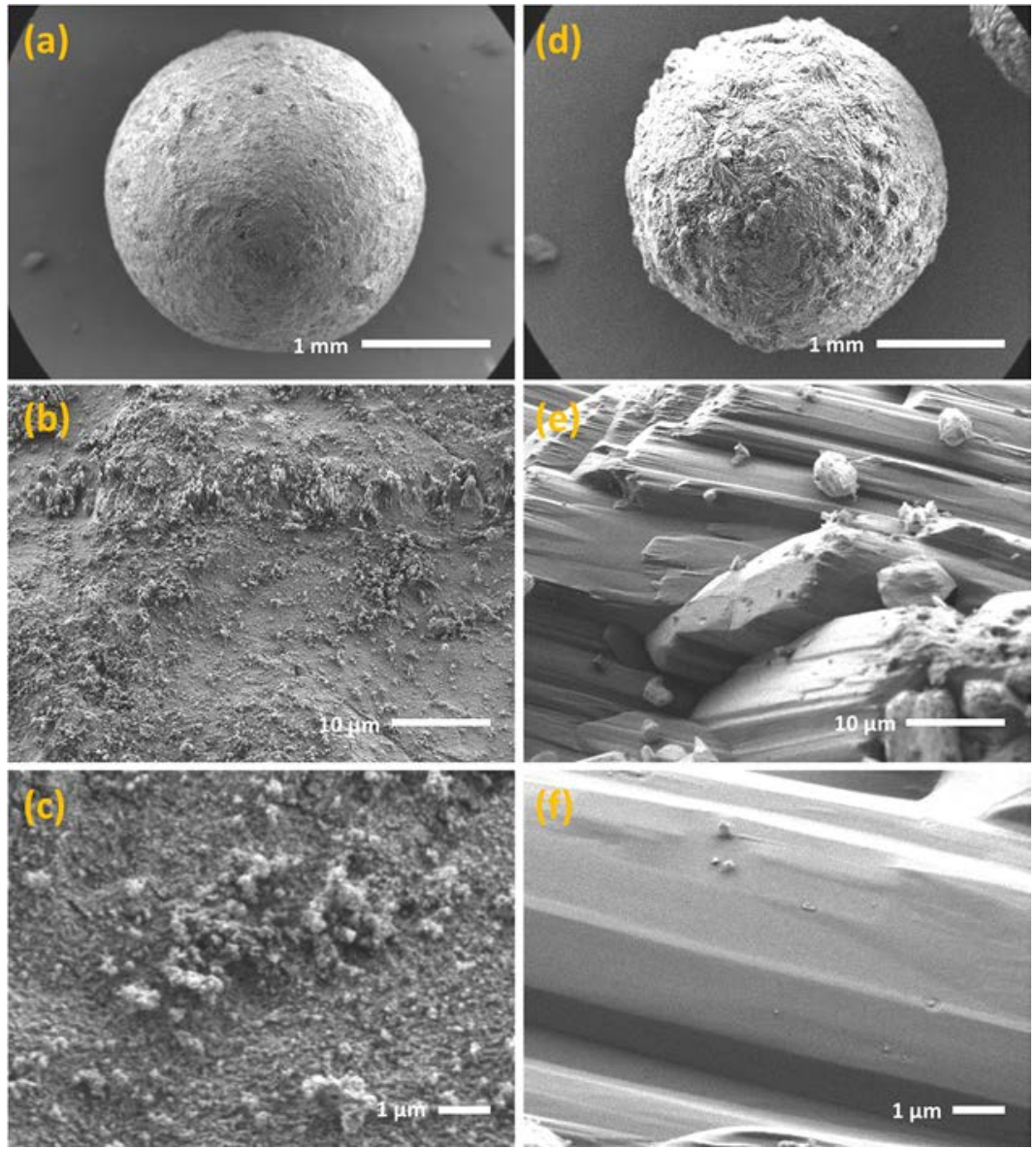

Figure 3. High-resolution FEG-SEM images (obtained with a JEOL microscope) of $(a-c)$ native alumina and (d-f) HQ-alumina composites; images a and $d$ show the entire particle, and $b, c$, e, and $f$ the particle surface.

media (i.e., no enclathration). The HQ seems to be totally deactivated and prohibits the enclathration of gas. In addition, on the basis of our previous observations, we can state that (i) single crystals of HQ clathrate obtained from crystallization in ethanol ${ }^{18}$ or clathrates prepared by gas-phase synthesis with $\mathrm{CH}_{4}$ or $\mathrm{CO}_{2}{ }^{14}$ are off-white opaque crystals after drying; (ii) the tint of HQ silica particles produced by wet and dry impregnation methods varies from white to light beige. ${ }^{17}$ Therefore, we used this qualitative argument to choose the protocol that gives clear colored composites rather than dark or black ones. It is likely that the color of the particles after impregnation is linked to specific interactions and/or reaction of the HQ with the alumina, which may induce oxidation of HQ during the drying step. ${ }^{19}$ This assumption was corroborated by adding sodium sulfite $\left(\mathrm{Na}_{2} \mathrm{SO}_{3}\right.$, a reducing agent well-known for its antioxidant properties) to the nonacidified impregnation solution $\left(\sim 0.5 \mathrm{~g}\right.$ for $\left.10 \mathrm{~cm}^{3}\right)$ : as shown in Figure $2 \mathrm{c}$, the addition of sodium sulfite changes the coloration of the $\mathrm{HQ}$-alumina composites obtained after drying from black (without the additive) to brown (with the additive). Among the various tests we carried out, only the acidification of the impregnation solution by sulfuric acid gave the lightest particle tint (light beige), as shown in Figure 2d.

Analytical Techniques. Both the native alumina and HQ-alumina composites are analyzed by means of several complementary analytical techniques in an attempt to cross-correlate the morphological and structural properties of the particles with their efficiency in relation to the targeted application. Scanning electron microscopy (SEM) serves to characterize the surface of the particles, whereas Xray computed tomography (XCT) is used for nondestructive inspection of the core of the alumina particles and for specifically analyzing the macroporosity of the particles. Nitrogen adsorptiondesorption (i.e., gas porosimetry) tests at $77 \mathrm{~K}$ are run to characterize the mesoporosity (pore size of 2-50 nm) of the HQ-alumina composite (i.e., specific area, total pore volume, and pore size distribution). The specific area is determined using the BrunauerEmmett-Teller (BET) method, ${ }^{20}$ whereas both the total pore volume and pore size distribution are calculated using the Barrett-JoynerHalenda (BJH) method. ${ }^{21}$ The density of the native alumina particles was measured by helium pycnometry. Thermogravimetric analysis (TGA) coupled with differential scanning calorimetry (DSC) is used to estimate the HQ content of the HQ-alumina composite material and measure the thermal signatures of the impregnated compounds. Spectroscopic techniques (i.e., Raman spectroscopy and solid-state ${ }^{13} \mathrm{C}$ nuclear magnetic resonance (NMR)), and XRD measurements, serve to identify the structure of the deposits. Using Raman spectroscopy, both the external surface and the cross-section of the impregnated particles can be investigated. Additional details concerning the apparatuses and methods used in this study are given in the Supporting Information.

Gas Capture Measurements. Both the gas capture kinetics and gas storage capacity of the $\mathrm{HQ}$ clathrates are quantified by gravimetric analysis in the presence of pure $\mathrm{CO}_{2}$ at $3.0 \mathrm{MPa}$ and $323 \mathrm{~K}$ using a Rubotherm magnetic suspension balance. The same apparatus was used in one of the authors' previous studies, ${ }^{17}$ and the reader is asked to refer to the corresponding paper for details on the apparatus and the experimental procedure.

Gas Separation Measurements. The experiments are conducted using an equimolar $\mathrm{CO}_{2} / \mathrm{CH}_{4}$ gas mixture at $3.0 \mathrm{MPa}$ and $323 \mathrm{~K}$ in a batch hydroquinone clathrate-based gas separation (HCBGS) process at bench scale. ${ }^{22}$ This process consists of a fixed bed reactor operating in closed loop mode (filled with the reactive enclathration media). The main instruments of the setup are a regulator expander, a Coriolis mass flowmeter, a gas circulator pump, a reactor, two coaxial heat 


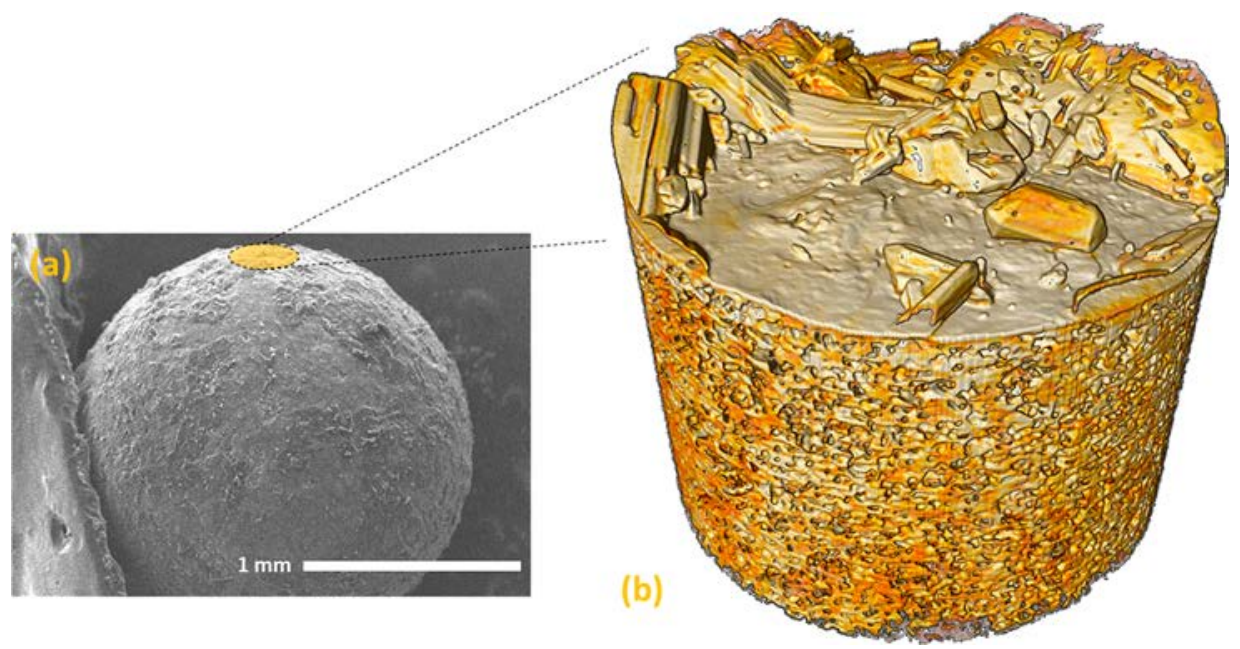

Figure 4. (a) Benchtop SEM image of an HQ-alumina composite (obtained with a Hirox microscope). (b) 3D false color XCT insert (275 $\mu \mathrm{m}$ in diameter) showing a detailed view of the HQ crystals scattered on the particle surface.
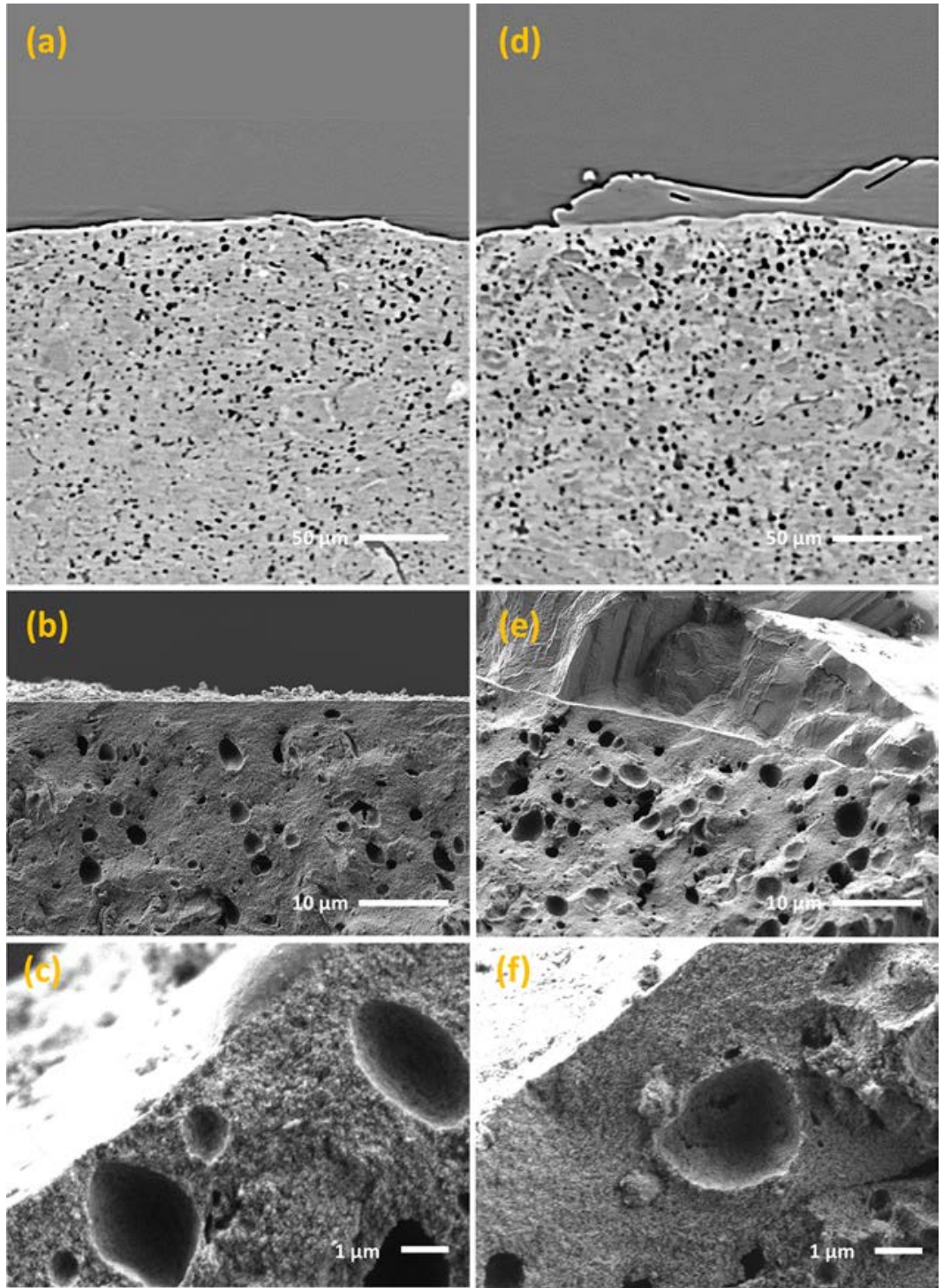

Figure 5. (a, d) XCT and (b, c, e, f) FEG-SEM images (obtained with a JEOL microscope) of native alumina (left) and HQ-alumina composites (right). 

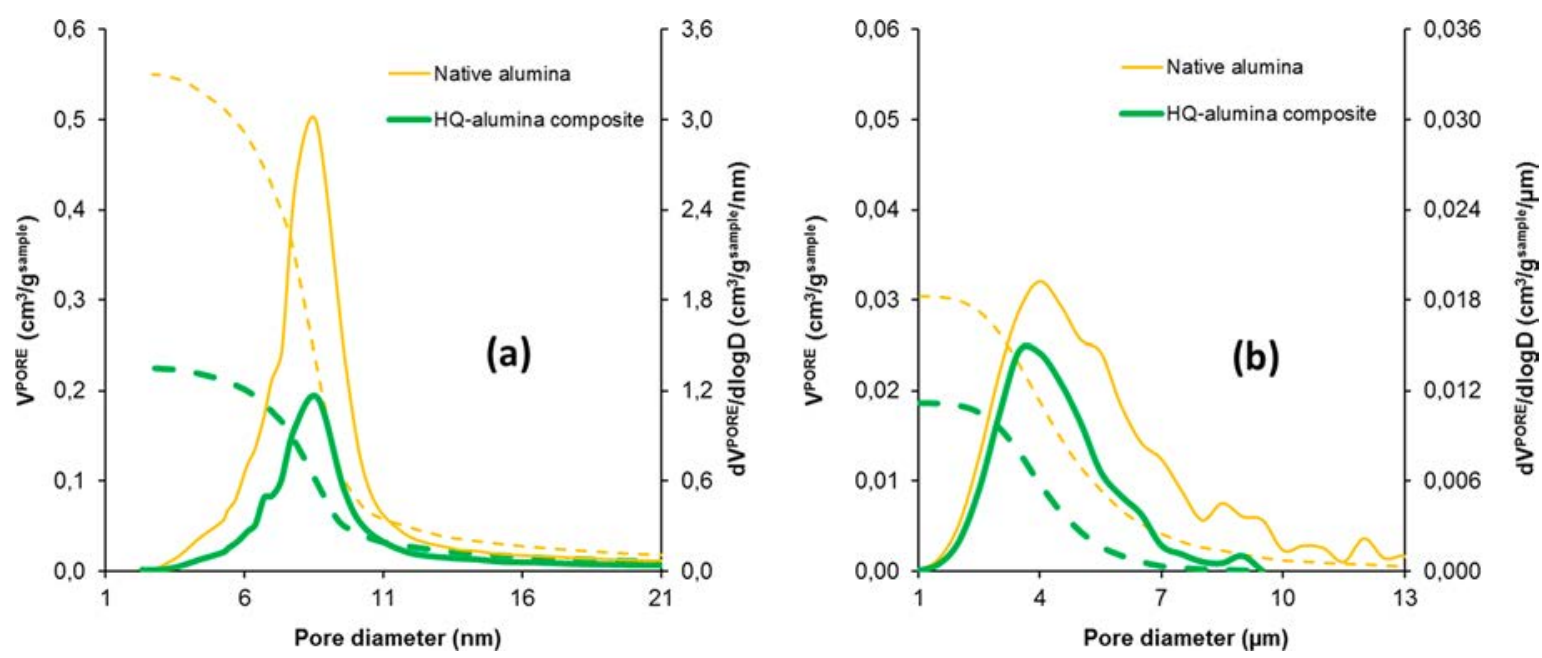

Figure 6. Pore-size distribution (solid line) and cumulative pore volume (dashed line) as a function of the pore diameter of native alumina (thin yellow lines) and of HQ-alumina composites (thick green lines). (a) Results obtained by $\mathrm{N}_{2}$ gas porosimetry; (b) results obtained by XCT.

exchangers, and a gas chromatograph (calibrated for quantitative measurements with different $\mathrm{CO}_{2} / \mathrm{CH}_{4}$ gas mixtures, with $0.3 \%$ relative uncertainty). In experiments like these in which gas clathrates are formed, both the pressure and gas composition are monitored over time to assess the reaction progress. Mass balance calculations are then performed to estimate the selectivity of the gas separation process toward $\mathrm{CO}_{2}$ (i.e., the preferential capture of $\mathrm{CO}_{2}$ from the gas mixture).

\section{RESULTS AND DISCUSSION}

3.1. Characterizing the HQ-Based Composite Materials. Figure 3 shows SEM images of the external surface of native alumina and HQ-alumina composites. The former has a relatively smooth appearance compared to the latter, which is covered with HQ crystals. A detailed 3D-image reconstruction of the HQ-alumina composite surface obtained by XCT is given in Figure 4. Cross-sections orthogonal to the particle surface obtained by XCT (Figure 5a, d) reveal the presence of macroporous cavities in both the native and the composite particles with a size distribution of around 3-4 $\mu \mathrm{m}$ (see Figure $6 \mathrm{~b})$. High-resolution SEM images of typical macropores taken on fractured particles are shown in Figure 5 b, c, e, and $\mathrm{f}$. The pore surface exhibits some asperities, but it is impossible to conclude based on the SEM images whether they are simply the rough surface of the alumina or a fine layer of HQ crystals.

Figure 6 presents the pore size distribution and cumulative pore volume of both the native and impregnated particles obtained by combining measurements of $\mathrm{N}_{2}$ adsorptiondesorption isotherms at $77 \mathrm{~K}$ using BET and $\mathrm{BJH}$ methods (Figure 6a) and XCT (Figure 6b). Using the density of 3.0423 $\mathrm{g} \mathrm{cm}^{-3}$ measured for the alumina particles, the macroporosity obtained by XCT is estimated at $0.030 \pm 0.006 \mathrm{~cm}^{3} \mathrm{~g}^{-1}$ for the native alumina particle and at $0.019 \pm 0.006 \mathrm{~cm}^{3} \mathrm{~g}^{-1}$ for the HQ-alumina composite. The $\mathrm{N}_{2}$ adsorption-desorption measurements determined that the mesoporous volume and specific area of the particles after impregnation were $0.22 \mathrm{~cm}^{3} /$ $\mathrm{g}$ and $63 \mathrm{~m}^{2} / \mathrm{g}$, respectively, hence values around $60 \%$ smaller than those of the native alumina particles (porous volume of $0.55 \mathrm{~cm}^{3} / \mathrm{g}$, and specific area of $177 \mathrm{~m}^{2} / \mathrm{g}$ ). As the mesoporous volume is $15-20$ times larger than the macroporous volume, the overall porosity reduction is close to $60 \%$ as well (see Table 1). The mean (meso)pore size of $9 \mathrm{~nm}$ and mean macropore size of 3-4 $\mu \mathrm{m}$ remained unchanged after the
Table 1. Pore Volume of Native Alumina and of HQAlumina Composites Obtained by $\mathrm{N}_{2}$ Gas Porosimetry and XCT

\begin{tabular}{llcc} 
& $\begin{array}{c}\text { native alumina } \\
\left(\mathrm{cm}^{3} \mathrm{~g}^{-1}\right)\end{array}$ & $\begin{array}{c}\text { HQ-alumina composite } \\
\left(\mathrm{cm}^{3} \mathrm{~g}^{-1}\right)\end{array}$ & $\begin{array}{c}\text { reduction } \\
(\%)\end{array}$ \\
mesoporosity & 0.55 & 0.22 & 60 \\
macroporosity & $0.030 \pm 0.006$ & $0.019 \pm 0.006$ & 37 \\
total & 0.58 & 0.24 & 59 \\
\hline
\end{tabular}

impregnation process (no peak shift). As already reported in one of the authors' ${ }^{17}$ previous studies, these observations suggest that either (i) the HQ crystals completely fill the $9 \mathrm{~nm}$ pores, (ii) or some of these pores are clogged by the deposited crystals, or (iii) the pores are partially filled, thereby reducing their height.

The TGA/DSC results presented in Figure 7 show the thermal behavior from 300 to $900 \mathrm{~K}$ of both the alumina

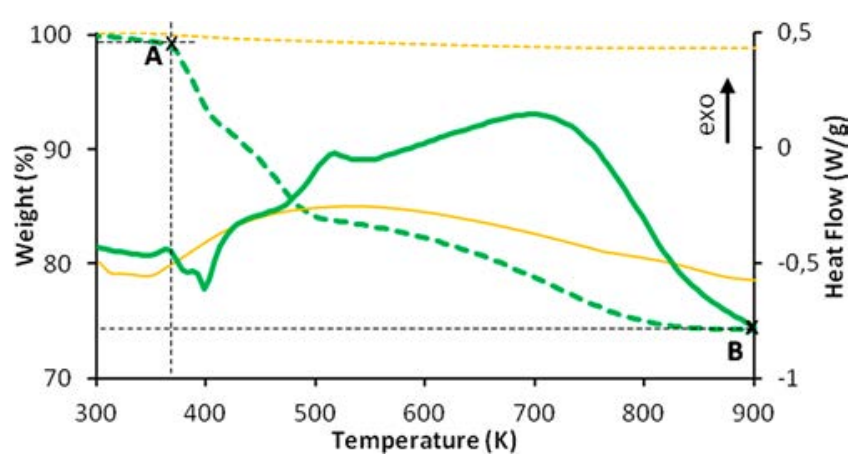

Figure 7. TGA (dashed line) and DSC (solid line) of native alumina particles after drying (fine yellow lines) and HQ-alumina composite (thick green lines).

particles (analyzed just before impregnation, i.e., after the first $24 \mathrm{~h}$ drying phase) and the HQ-alumina composite. The weight loss of the alumina particles after drying is less than 1 wt \%. The HQ content $(\tau)$ of the HQ-alumina composite is estimated from the TGA curve using eq 1 :

$$
\tau=\frac{W_{\mathrm{i}}-W_{\mathrm{f}}}{W_{\mathrm{f}}}
$$


where $W_{\mathrm{i}}$ is the sample weight (in \%) measured after the evaporation of ethanol (Figure 5, point $\mathrm{A}$ ) and $W_{\mathrm{f}}$ is the weight (\%) after the total mass loss (Figure 5, point B). Based on Figure 5, $W_{\mathrm{i}}$ and $W_{\mathrm{f}}$ are 99.29 and $74.04 \%$, respectively. The HQ content of the HQ-alumina composite is therefore estimated at $\tau=0.34 \pm 0.01 \mathrm{~g}^{\mathrm{HQ}} / \mathrm{g}^{\text {Alumina }}$.

Looking at the DSC curve (solid green line in Figure 7), there is a first light exotherm with an onset temperature of about $348 \mathrm{~K}$, then an endothermal phenomenon takes place from 360 to $450 \mathrm{~K}$, whereas exothermal trends are finally observed above $470 \mathrm{~K}$. The first exotherm may be ascribed to the beginning of partial HQ oxidation or dehydration followed by evaporation of the water formed in this process. In the presence of sulfuric acid and at high temperature, the alumina media may promote catalytic oxidation/dehydration of $\mathrm{HQ}^{23}$ The following endothermal and exothermal trends can be ascribed to the sublimation and fusion of $H Q$, followed by the degradation and volatilization of the residual $\mathrm{HQ} .^{17,24,25}$ It is worth noting that the thermal profile reported is somewhat similar to that of the HQ-silica composite, ${ }^{17}$ but in this case the aforementioned phenomena are shifted to lower temperatures. For instance, the endothermal phenomenon starts at $433 \mathrm{~K}$ for the silica-based composite (a value around $73 \mathrm{~K}$ higher than for the alumina-based composite). This can probably be attributed to the size of the impregnated HQ crystals that ensures better heat transfer (smaller HQ crystals in the case of the HQ-alumina composite), but also because alumina in the presence of sulfuric acid additive is a much more active catalyst than silica. ${ }^{23}$ In addition, from about 500 to $900 \mathrm{~K}$ - the maximum temperature-the HQ-alumina composite loses about $10 \%$ mass against less than $1 \%$ in the case of the HQ-silica composite. This major difference means that the impregnated HQ crystals of the HQ-alumina composite require higher temperatures to empty the mesopores of the support. The confined porous space appears to modify the thermodynamic equilibrium properties of the HQ as observed in other systems. ${ }^{26,27}$ All these observations confirm that chemical interactions occur between the HQ and the alumina particles and potentially that HQ crystals are present in the pores.

Figure $8 \mathrm{~d}$, e presents Raman spectra of both the external surface and the cross-section of the impregnated particles. To make a comparison with other data obtained previously by the authors, we show the spectra of native $\alpha-\mathrm{HQ}^{15} \mathrm{CO}_{2}-\mathrm{HQ}$ clathrate, ${ }^{14}$ and guest-free clathrate obtained by thermal release of $\mathrm{CO}_{2}$ from a $\mathrm{CO}_{2}$-HQ clathrate ${ }^{15}$ in Figure $8 \mathrm{a}-\mathrm{c}$, respectively. Focusing on the range 1100 to $1700 \mathrm{~cm}^{-1}$, some characteristic differences with the Raman spectrum of native $\mathrm{HQ}$ can be observed. The two $\mathrm{C}-\mathrm{H}$ bending bands at 1163 and $1169 \mathrm{~cm}^{-1}$ in the native HQ spectrum appeared as a single band at $1163 \mathrm{~cm}^{-1}$ in the HQ-alumina composite spectrum. The intensities of the two bands at 1252 and 1274 $\mathrm{cm}^{-1}$ in the native HQ spectrum are significantly reduced in the HQ-alumina composite spectrum, and the coupled $\mathrm{C}-\mathrm{O}$ and $\mathrm{C}-\mathrm{C}$ stretching band is shifted from 1257 to $1261 \mathrm{~cm}^{-1}$. In addition, there are characteristic changes in the relative intensities of the three $\mathrm{C}-\mathrm{C}$ stretching bands at around 1600 $\mathrm{cm}^{-1}$ (these changes are less pronounced in the case of the composite's external surface spectrum). Consequently, in comparison to the spectrum previously obtained for a $\mathrm{HQ}$ clathrate structure (see Figure $8 \mathrm{~b}$ ) and with literature data, ${ }^{28}$ all these differences are in perfect agreement with the signature of the HQ clathrate form in the composite. Note that in the

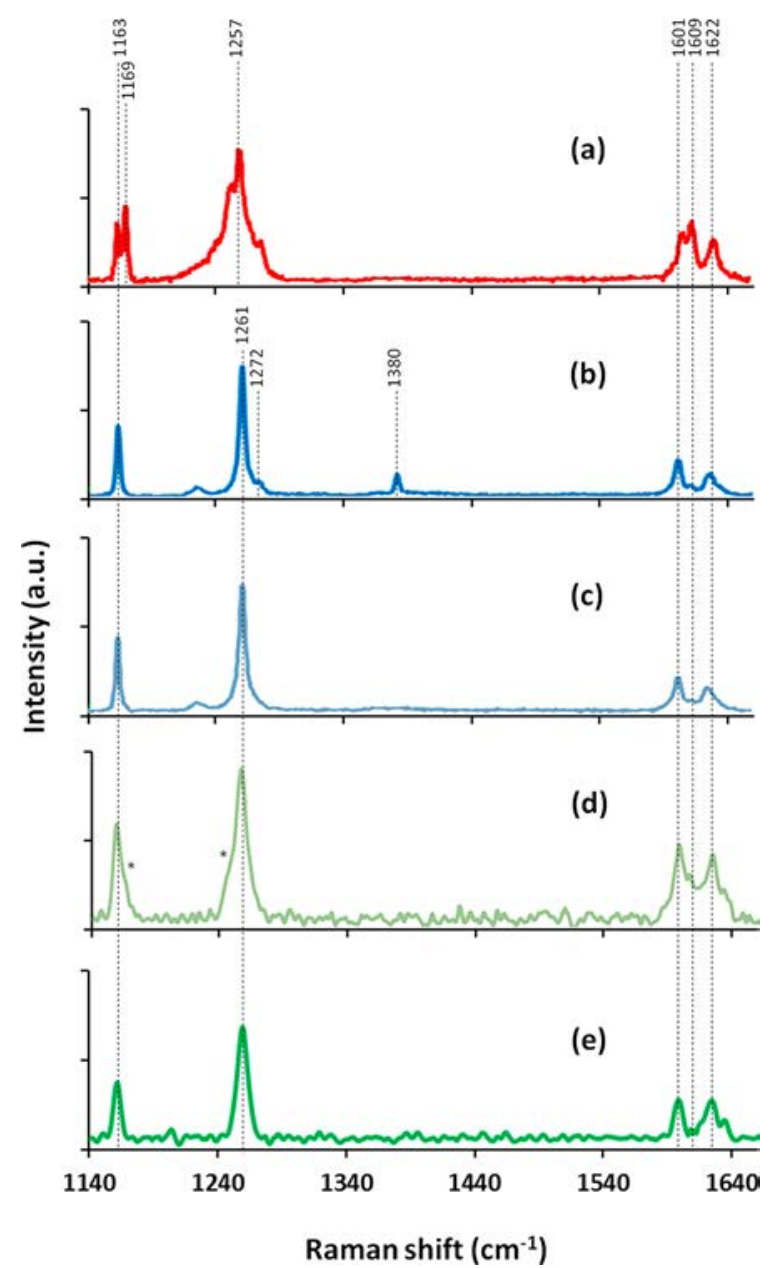

Figure 8. Raman spectra of (a) native $\alpha$-HQ data from ref 15; (b) $\mathrm{HQ}-\mathrm{CO}_{2}$ clathrate, data from ref 14 ; (c) guest-free HQ clathrate, data from ref 15; (d) external surface of the HQ-alumina composite particle, the asterisks show slight shoulders at $\sim 1169$ and $\sim 1252 \mathrm{~cm}^{-1}$ visible on the spectra; (e) cross-section of the HQ-alumina composites particle.

case of the composite's external surface spectrum, the slight shoulders seen both at $1169 \mathrm{~cm}^{-1}$ (on the right side of the band at $1163 \mathrm{~cm}^{-1}$ ) and at $1252 \mathrm{~cm}^{-1}$ (on the left side of the band at $1261 \mathrm{~cm}^{-1}$ ) show that traces of $\alpha$-HQ are present on the particle surface (see the asterisks in Figure $8 \mathrm{~d}$ ).

So, our Raman spectroscopic data suggest that (i) the external surface is covered with guest-free HQ clathrate crystals and traces of native $\alpha-\mathrm{HQ}_{i}$ (ii) only the guest-free HQ clathrates are present inside the particle, as only their spectral signature is found on the particle cross-section. In fact, finding a Raman spectroscopic signature of HQ on the cross-section of the impregnated particles is additional proof that $\mathrm{HQ}$ is present in the pores of the alumina support core, corroborating the conclusions made from modifications to the pore-size distribution and cumulative pore volume between the native and impregnated particles, deduced from Figure 6. To explain the presence of the spectral signature of a possible guest-free clathrate structure, one could assume that it was initially stabilized by some of the molecules originally present in the solution or in the gas phase during the synthesis. However, no spectral signatures of $\mathrm{H}_{2} \mathrm{SO}_{4}\left(\nu_{\mathrm{H} 2 \mathrm{SO} 4}=977,892,592\right.$, and 429 $\left.\mathrm{cm}^{-1}\right),{ }^{29} \mathrm{O}_{2}\left(\nu_{\mathrm{O} 2}=1550 \mathrm{~cm}^{-1}\right)$ or $\mathrm{N}_{2}\left(\nu_{\mathrm{N} 2}=2326 \mathrm{~cm}^{-1}\right)^{30}$ were detected by Raman spectroscopy, suggesting that none of 
these products are present as guests in the final composite material and that this clathrate structure is effectively a guestfree one.

Similarly, the comparison in Figure 9 between solid-state ${ }^{13} \mathrm{C}$ $\mathrm{NMR}$ analyses made on $\alpha$-HQ $\mathrm{CO}_{2}$-HQ clathrates, ${ }^{14}$ and

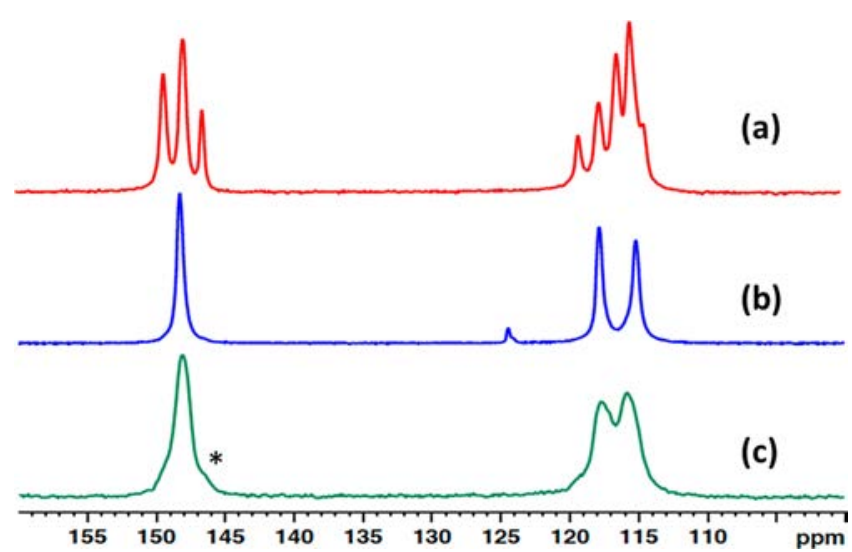

Figure 9. ${ }^{13} \mathrm{C}$ NMR spectra: (a) native $\alpha-\mathrm{HQ}$ (b) $\mathrm{CO}_{2}-\mathrm{HQ}$ clathrate, ${ }^{14}$ and (c) HQ-alumina composite.

HQ-alumina composite clearly reveals the nature of the crystals present in the impregnated particles. In the range of 110-150 ppm, only three peaks are expected in the ${ }^{13} \mathrm{C}$ spectra of the $\beta$ form of $\mathrm{HQ}$ because of the ideal centro-symmetric cage symmetry. ${ }^{31}$ However, the exact chemical shift values of these three peaks vary over a narrow range of values and depend on the nature of the guest and the degree of occupancy of the cages. ${ }^{32}$ The NMR spectra of Figure 9c effectively exhibit three distinct peaks at $148.1,117.7$, and $115.8 \mathrm{ppm}$ corresponding to the chemical shifts of the HQ clathrates. No guest-molecule signature is measured over the entire spectra, such as, for example, the $\mathrm{CO}_{2}$ signature in the $\mathrm{CO}_{2}$-HQ clathrate at 124 ppm (see Figure 9b). As shown in Figure 9c, the enlargement of the peak bases compared to pure $\mathrm{CO}_{2}-\mathrm{HQ}$ clathrate, the tiny shoulder distinguishable at $146.5 \mathrm{ppm}$ on the composite spectra (see the asterisk in the figure), and the merged bases of the two peaks at 117.7 and $115.8 \mathrm{ppm}$ confirm the presence of traces of $\alpha-\mathrm{HQ}$ as already found on the particle surface with Raman analysis.

Interestingly enough, the distance $\Delta$ (in ppm) between the two peaks of the nonsubstituted carbon atoms (between $\sim 115$ and $117 \mathrm{ppm}$ ) can provide additional elements on the shape of the cavity. As a check, the distance $\Delta$ in Figure 9 is measured for $\mathrm{CO}_{2}$-HQ clathrates at $2.5 \mathrm{ppm}$; this is in very good agreement with the data obtained by Lee et al., ${ }^{33}$ who found $2.6 \mathrm{ppm}$ for the same system. Concerning the clathrate form found in the composite, the mean separation of these two peaks is $\Delta=1.9 \mathrm{ppm}$, a value slightly higher than those found by Lee et al. for HQ clathrates formed with $\mathrm{CH}_{4}(\Delta=1.7)$ ppm and $\mathrm{N}_{2}(\Delta=1.8 \mathrm{ppm}) .^{33}$ Therefore, we can infer from our NMR results that the guest-free clathrate formed in this composite has a structure close to that of type I HQ clathrates, generally obtained with small guests such as $\mathrm{Ar}, \mathrm{Kr}, \mathrm{Xe}, \mathrm{CH}_{4}$, and $\mathrm{N}_{2}$, and possessing nondeformed (or only slightly deformed) cavities. $^{34,35}$

To obtain more precise crystallographic information, we collected powder XRD data. The results obtained for $\alpha-\mathrm{HQ}$ native alumina particles, and impregnated particles are presented in Figure 10. For the HQ that served as the raw material for the impregnation, the pattern of the $\alpha$-form of HQ (Figure 10a) is easily identified, with lattice parameters calculated to be $a=b=38.330(14) \AA$ and $c=5.6450(22)$ $\AA$ in the space group $R \overline{3}$. Concerning the impregnated particles, the analysis was performed 2 years and 6 months later than the first set of analyses, on the same batch of impregnated particles (stored in a closed plastic bag, away from light, under ambient temperature and pressure conditions). The particles were ground in a mortar and the powder obtained was analyzed immediately by XRD. In Figure $10 \mathrm{~b}$, the pattern obtained clearly shows the signature of HQ clathrates (i.e., the $\beta$-form), ${ }^{36}$ superimposed onto that of the amorphous alumina support (Figure 10c). The lattice parameters are calculated to be $a=b=16.469(20) \AA$ and $c$ $=5.5197(59) \AA \AA$ in the space group $R \overline{3}$, in good agreement with the very sparse data reported in the literature for guest-free HQ clathrate structures $(a=b=16.613(3) \AA$ and $c=5.4746(5) \AA$

(a)

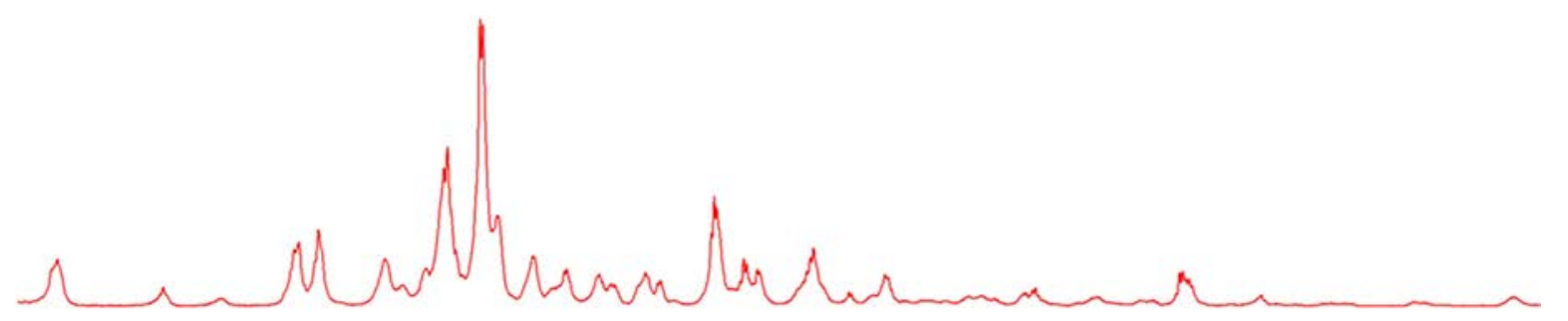

(b)

(c)

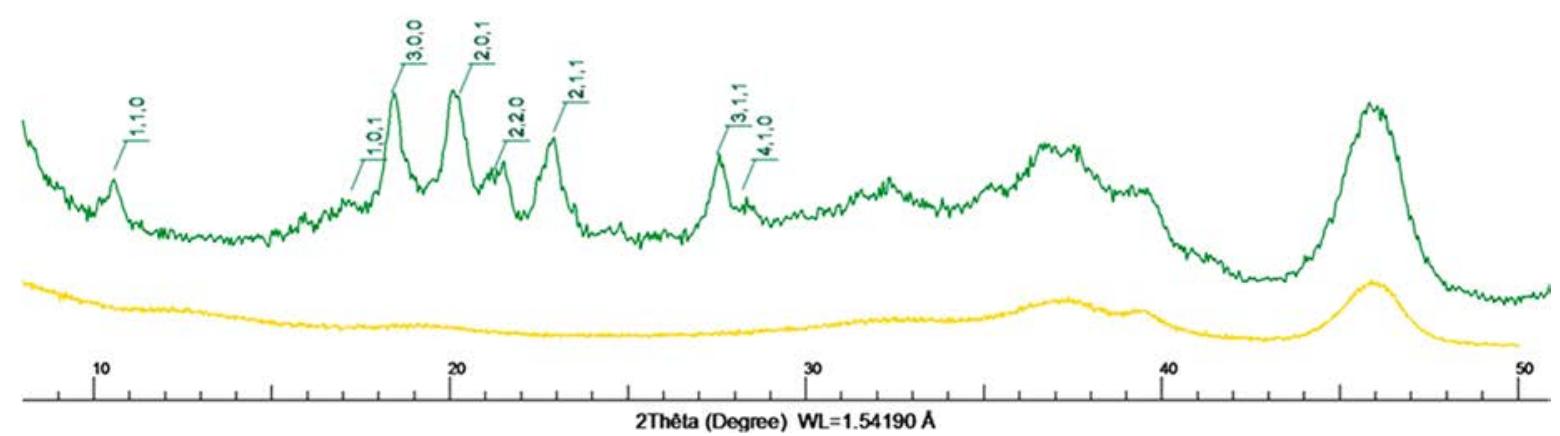

Figure 10. XRD patterns recovered at ambient conditions: (a) native $\alpha$-HQ (b) HQ-alumina composite, (c) native alumina particles. 
in Mak and Lam (2004), ${ }^{34}$ and $a=b=16.60(1) \AA$ and $c=$ 5.52(1) $\AA$ in Han et al. $\left.(2012)^{36}\right)$. These lattice parameter values confirm that the guest-free clathrate structure formed in this composite may be of type I, with no (or only slight) lattice distortion of the cavity, ${ }^{37}$ in perfect line with our conclusions from NMR measurements. Actually, one of the most interesting features revealed by this XRD analysis is that the guest-free clathrate structure formed during the impregnation process is very stable, as it is still present in the particles more than 2 years after their synthesis. However, the reasons why this could happen have not yet been elucidated. The specific molecular arrangement of the HQ molecules might be related to specific interactions occurring between the HQ and the alumina support, or to confinement effects into the pores. Further investigations are necessary to clarify this point.

3.2. Use of HQ-Based Composite Materials. The HQalumina composite materials are used to perform $\mathrm{CO}_{2}$ capture experiments at $3.0 \mathrm{MPa}$ and $323 \mathrm{~K}$. The composite captured around $0.45 \mathrm{~mol}^{\mathrm{CO} 2} / \mathrm{kg}^{\text {Media }}$ of $\mathrm{CO}_{2}$ after about 10 days on stream. Note that, knowing the HQ content of the composite $\left(0.34 \mathrm{~g}^{\mathrm{HQ}} / \mathrm{g}^{\text {Alumina }}\right)$ and the maximum gas storage capacity of $\mathrm{HQ}\left(3.03 \mathrm{~mol}^{\mathrm{GAS}} / \mathrm{kg}^{\mathrm{HQ}}\right)$, calculated on the basis of the general HQ clathrate stoichiometry of 1 molecule of gas per 3 molecules of $\mathrm{HQ}^{1,2}$ ), the maximum gas storage capacity of the HQ-alumina composite is an estimated $0.77 \mathrm{~mol}^{\mathrm{GAS}} / \mathrm{kg}^{\text {Media }}$.

The $\mathrm{CO}_{2}$ adsorption capacity of the native alumina particles is also measured. The equilibrium plateau is reached in $6 \pm 3$ min and a storage capacity of $1.48 \mathrm{~mol}^{\mathrm{CO} 2} / \mathrm{kg}^{\text {Alumina }}$ is measured. As a result, considering these adsorption data for the native support, the amount of gas captured by adsorption on the HQ-alumina composites is graphically estimated at 0.06 $\mathrm{mol} \mathrm{CO}^{\mathrm{C}} / \mathrm{kg}^{\text {Media }}$. This amount of gas is subtracted from the total amount of $\mathrm{CO}_{2}$ captured by the composite materials, so that only the effect of the HQ crystals present on the alumina particles is considered (i.e., to monitor only the $\mathrm{CO}_{2}$ capture kinetics generated by the enclathration reaction). The methodology and hypothesis underlying this calculation were validated in one of the authors' previous studies. ${ }^{17}$ In short, the main assumptions are (i) the kinetics of $\mathrm{CO}_{2}$ adsorption on the HQ-based composite are much faster than the enclathration kinetics, meaning that the amount of gas adsorbed and the amount of gas enclathrated can be differentiated, and (ii) the time needed to reach the equilibrium adsorption plateau is the same for both the native support and the HQ-based composite.

The results obtained with the alumina composites are first compared with those of silica-based composites and then with those of powdered native HQ (Figure 11). As previously observed for HQ-silica composites, the induction time (i.e., the time needed to initiate the HQ clathrate formation) can be done away with by using HQ-alumina composites. The enclathration rate $\left(r_{c}\right)$ is $1.6 \mathrm{mmol}^{\mathrm{CO} 2} /\left(\mathrm{kg}^{\mathrm{HQ}} \mathrm{min}\right)$, and the characteristic time $\left(t_{c}^{50}\right)$ needed to attain a clathrate occupancy of $50 \%$ is about 8 days, which is a slight improvement compared to powdered $\mathrm{HQ}$ ( $r_{\mathrm{c}}$ of $0.5 \mathrm{mmol}^{\mathrm{CO} 2} /\left(\mathrm{kg}^{\mathrm{HQ}} \min \right)$ and $t_{\mathrm{c}}^{50}$ of 9.1 days). It is clear, however, that the HQ-alumina composites cannot compete in terms of enclathration kinetics with HQ-silica composites $\left(r_{\mathrm{c}}\right.$ of $19 \mathrm{mmol}^{\mathrm{CO} 2} /\left(\mathrm{kg}^{\mathrm{HQ}} \min \right)$ and $t_{\mathrm{c}}^{50}$ of 0.4 days). The presence of guest-free HQ clathrates in the HQ-alumina composites does not seem to have any significant effect on the enclathration kinetics. The gas-HQ contact area available for enclathration is probably not big enough to allow any substantial improvement in terms of kinetics compared to the powdered HQ. In addition, as

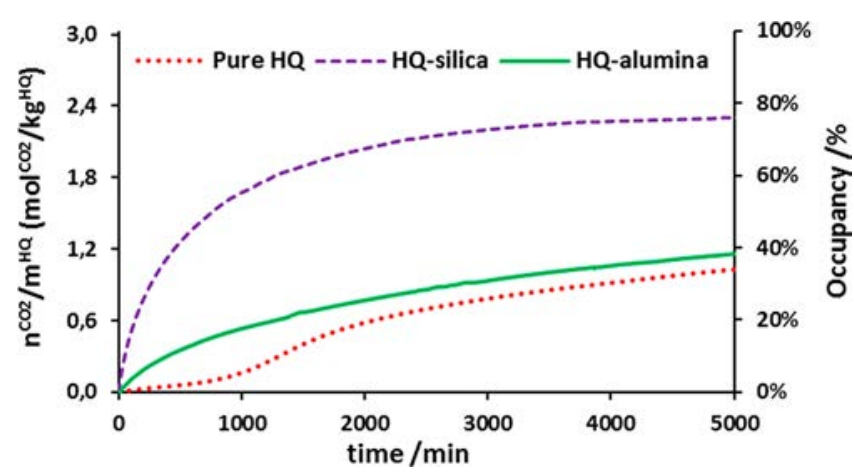

Figure 11. Mole number of $\mathrm{CO}_{2}$ captured by enclathration (at 3.0 $\mathrm{MPa}$ and $323 \mathrm{~K}$ ) normalized by the mass of impregnated $\mathrm{HQ}$ as a function of time: native HQ powder (dotted red line), HQ-silica composite (dashed purple line), and HQ-alumina composite (solid green line).

reported in the literature, ${ }^{38,39} \mathrm{HQ}$ clathrate formation is potentially impacted when it takes place in confined porous space.

To study the potential of these materials for gas separation, we ran HCBGS experiments on the HQ-alumina composite materials using an equimolar $\mathrm{CO}_{2} / \mathrm{CH}_{4}$ gas mixture at 3.0 $\mathrm{MPa}$ and $323 \mathrm{~K}$ for 4 days. Table 2 presents the main results

Table 2. Material Performance in an HCBGS Process with an Equimolar $\mathrm{CO}_{2} / \mathrm{CH}_{4}$ Mixture at 3.0 MPa and $323 \mathrm{~K}$ in Terms of the $\mathrm{CO}_{2}$ Mole Fraction in the Stored Gas $\left(x^{\mathrm{CO} 2}\right)$, Separation Factor (S.F. ${ }^{\mathrm{CO} 2 / \mathrm{CH} 4}$ ), Transient Storage Capacity $(q)$, and Time Needed to Reach the Transient Storage Capacity $\left(t_{q}\right)$

\begin{tabular}{lcrcl}
\multicolumn{1}{c}{ media } & \multicolumn{1}{c}{$x^{\mathrm{CO} 2}$} & S.F. ${ }^{\mathrm{CO} 2 / \mathrm{CH} 4}$ & $\begin{array}{c}q(\mathrm{~mol} / \\
\left.\mathrm{kg}^{\text {Media }}\right)\end{array}$ & \multicolumn{1}{c}{$t_{q}$} \\
HQ & $0.82 \pm 0.04$ & $5.2 \pm 0.6$ & $0.82 \pm 0.05$ & 4 days \\
silica & $0.86 \pm 0.08$ & $5.9 \pm 2.4$ & $0.06 \pm 0.01$ & $6 \pm 3 \mathrm{~min}$ \\
HQ-silica & $0.83 \pm 0.03$ & $6.6 \pm 1.0$ & $0.64 \pm 0.02$ & 4 days \\
alumina & $0.83 \pm 0.08$ & $5.5 \pm 2.1$ & $0.63 \pm 0.06$ & $6 \pm 3$ min \\
HQ-alumina & $0.91 \pm 0.03$ & $10.7 \pm 1.0$ & $0.21 \pm 0.02$ & 4 days \\
\hline
\end{tabular}

deduced from the HCBGS measurements: (i) the mole fraction of $\mathrm{CO}_{2}$ in the stored gas $\left(x^{\mathrm{CO}}\right)$; (ii) the separation factor (S.F. ${ }^{\mathrm{CO} 2 / \mathrm{CH} 4}$ ), which quantifies the selectivity of the separation process toward $\mathrm{CO}_{2}{ }^{22,40}$ (the larger the S.F., the more selective the separation); and (iii) the transient storage capacity $(q)$, i.e., the ratio of the amount of gas stored at time $t_{q}$ to the mass of reactive medium (i.e., HQ + alumina).

$\left(\mathrm{S.F} .^{\mathrm{CO} 2 / \mathrm{CH} 4}\right)$ is obtained using eq 2 :

$$
\text { S. F. }{ }^{\mathrm{CO} 2 / \mathrm{CH} 4}=\frac{x^{\mathrm{CO} 2} /\left(1-x^{\mathrm{CO} 2}\right)}{y^{\mathrm{CO} 2} /\left(1-y^{\mathrm{CO} 2}\right)}
$$

where $x^{\mathrm{CO} 2}$ and $y^{\mathrm{CO} 2}$ are the $\mathrm{CO}_{2}$ molar compositions of the $\mathrm{CO}_{2} / \mathrm{CH}_{4}$ gas mixture at time $t_{q}$ in the gas stored in the medium and in the gas phase, respectively.

The performance of the HQ-alumina composites in terms of $\mathrm{CO}_{2} / \mathrm{CH}_{4}$ separation is compared to those of pure $\mathrm{HQ}$ powder, native alumina, native silica, and HQ-silica composites. With the highest S.F. ${ }^{\mathrm{CO} 2 / \mathrm{CH} 4}$ value, 10.7 , the HQ-alumina composite material exhibits preferential capture of $\mathrm{CO}_{2}$ molecules over time: it exceeds the performance of the HQsilica composites $\left(\mathrm{S} . \mathrm{F}^{\mathrm{CO} 2 / \mathrm{CH} 4}=6.6\right)$ and is approximately twice as selective as the HQ powder. However, the $q$ value of the 
HQ-alumina composites measured after 4 days $(0.21 \mathrm{~mol} / \mathrm{kg})$ is found to be much lower than those of pure HQ and HQsilica composites $(0.82$ and $0.64 \mathrm{~mol} / \mathrm{kg}$ respectively). It can therefore be concluded that this novel HQ-alumina composite exhibits enhanced selectivity toward $\mathrm{CO}_{2}$, probably related to the presence of guest-free clathrate structures directly formed inside the particle. However, because of its low storage capacity and weak kinetic performances, further material improvements are still necessary before this type of composite can be considered for industrial applications.

\section{CONCLUSIONS}

This study has provided experimental data on the preparation and characterization of HQ-alumina composite materials able to form gas clathrates, and their use for $\mathrm{CO}_{2}$ separation. Characterization of these composites confirmed that HQ was deposited on the alumina particles (both on the external surface and in the particle pores), and revealed very interesting and unusual features. Even if direct crystallization of a guestfree clathrate structure is highly unusual, it is therefore demonstrated using all the characterization results that such a structure is directly crystallized in the core of the alumina particles during the impregnation process. Very interestingly, this guest-free clathrate structure was found to be very stable (over 2 years) in these conditions. On the basis of the kinetic experiments performed using pure $\mathrm{CO}_{2}$, we observed that the HQ-alumina composites presented a slightly improved enclathration rate compared to $\mathrm{HQ}$ powder. In addition, when these composites are used with an equimolar $\mathrm{CO}_{2} / \mathrm{CH}_{4}$ gas mixture, preferential capture of $\mathrm{CO}_{2}$ molecules over time is observed, and the separation factor is approximately double those obtained with HQ powder or HQ-silica composites. The use of these composite materials, allowing the formation of organic clathrates directly by gas/solid reaction (solvent-free), opens up promising avenues for developing alternative clathrate-based processes for $\mathrm{CO}_{2}$ capture, storage, and separation. Although the presence of a stable guest-free clathrate structure in these materials is a very interesting option to greatly enhance the selective capture of gaseous substance in HQ clathrates, further improvements to the particle characteristics are still necessary, in particular for boosting the gas capture kinetics and storage capacity, to foresee potential use in practical applications at larger scale.

\section{ASSOCIATED CONTENT}

\section{SI Supporting Information}

The Supporting Information is available free of charge at https://pubs.acs.org/doi/10.1021/acsami.0c06187.

Characterization apparatuses and methods: scanning electron microscopy, helium pycnometry, X-ray computed tomography, nitrogen adsorption-desorption tests, thermogravimetric analysis coupled with differential scanning calorimetry, raman spectroscopy, nuclear magnetic resonance, and powder X-ray diffraction (PDF)

\section{AUTHOR INFORMATION}

\section{Corresponding Author}

Jean-Philippe Torré - CNRS, INPT, UPS, Laboratoire de Génie Chimique, Université de Toulouse, Toulouse 31013, France; 이 orcid.org/0000-0001-5735-8626; Email: jeanphilippe.torre@ensiacet.fr

\section{Authors}

Romuald Coupan - E2S UPPA, CNRS, Total, LFCR, Universite de Pau et des Pays de l'Adour, Pau 64012, France; Total Research \& Technology Feluy, Seneffe 7181, Belgium; (1) orcid.org/0000-0001-7542-0374

Peter Moonen - E2S UPPA, CNRS, Total, LFCR and E2S UPPA, CNRS, DMEX, Université de Pau et des Pays de l'Adour, Pau 64012, France

Christophe Dicharry - E2S UPPA, CNRS, Total, LFCR, Universite de Pau et des Pays de l'Adour, Pau 64012, France; (1) orcid.org/0000-0002-6318-3989

Frédéric Plantier - E2S UPPA, CNRS, Total, LFCR, Universite de Pau et des Pays de l'Adour, Anglet 64600, France Joseph Diaz - E2S UPPA, CNRS, Total, LFCR, Université de Pau et des Pays de l'Adour, Pau 64012, France

Eve Péré - E2S UPPA, CNRS, IPREM, Université de Pau et des Pays de l'Adour, Pau 64012, France

Abdel Khoukh - E2S UPPA, CNRS, IPREM, Université de Pau et des Pays de l'Adour, Pau 64012, France

Fabrice Guerton - E2S UPPA, CNRS, DMEX, Universite de Pau et des Pays de l'Adour, Pau 64012, France

Pascale Sénéchal - E2S UPPA, CNRS, DMEX, Université de Pau et des Pays de l'Adour, Pau 64012, France

Cédric Charvillat - CNRS, INPT, UPS, CIRIMAT, Université de Toulouse, Toulouse, France

Marie-Line De Solan - CNRS, INPT, UPS, Laboratoire de Génie Chimique, Université de Toulouse, Toulouse 31013, France

Complete contact information is available at: https://pubs.acs.org/10.1021/acsami.0c06187

\section{Author Contributions}

The manuscript was written based on contributions from all the authors. All the authors have given their approval to the final version of the manuscript.

\section{Funding}

The authors thank the Gas Solutions department of Total S.A. (Exploration \& Production Branch) for its financial support.

\section{Notes}

The authors declare no competing financial interest.

\section{ACKNOWLEDGMENTS}

The authors gratefully acknowledge the work group involved in the ORCHIDS project, the Carnot Institute ISIFoR (Institute for Sustainable Engineering of Fossil Resources), and TOTAL. The tomographic acquisitions described in this article were performed using an instrument provided by TOTAL. We extend our thanks to S. Labat and V. Pellerin from the IPREM laboratory and to G. Guittier and C. Rey-Rouch from the Service Analyse et Procédés (SAP) of the LGC in Toulouse, for their help with the analysis.

\section{ABBREVIATIONS}

HQ hydroquinone; HCBGS, hydroquinone clathrate-based gas separation; SEM, scanning electron microscopy; FEG, field-emission gun; TGA, thermogravimetric analysis; DSC, differential scanning calorimetry; NMR, nuclear magnetic resonance; XCT, X-ray computed tomography; XRD, X-ray diffraction 


\section{REFERENCES}

(1) Atwood, J. L.; Steed, J. W. Encyclopedia of Supramolecular Chemistry; CRC Press, Taylor \& Francis Group: Boca Raton, FL, 2004; Vol. 1.

(2) Atwood, J. L.; Davies, J. E. D.; McNicol, D. D. Structural Aspects of Inclusion Compounds formed by Organic Host lattices; Academic Press: London, 1984; Vol. 2.

(3) Sloan, E. D.; Koh, C. A. Clathrate Hydrates of Natural Gases, 3rd ed.; CRC Press, Taylor \& Francis Group: Boca Raton, FL, 2008.

(4) Rozsa, V. F.; Strobel, T. A. J. Triple Guest Occupancy and Negative Compressibility in Hydrogen-Loaded $\beta$-Hydroquinone Clathrate. J. Phys. Chem. Lett. 2014, 5, 1880-1884.

(5) Coupan, R.; Dicharry, C.; Torré, J.-P. Hydroquinone Clathrate Based Gas Separation (HCBGS): Application to the $\mathrm{CO}_{2} / \mathrm{CH}_{4}$ Gas Mixture. Fuel 2018, 226, 137-147.

(6) Lee, J.-W.; Poudel, J.; Cha, M.; Yoon, S. J.; Yoon, J.-H. Highly Selective $\mathrm{CO}$ Extraction from a Mixture of $\mathrm{CO}_{2}$ and $\mathrm{H}_{2}$ Gases using Hydroquinone Clathrates. Energy Fuels 2016, 30, 7604-7609.

(7) Chleck, D. J.; Ziegler, C. A. The Preparation and some Properties of Radioactive Quinol-Krypton Clathrate Compounds. Int. J. Appl. Radiat. Isot. 1959, 7, 141-144.

(8) Evans, D. F.; Richards, R. E. Preparation and Magnetic Susceptibility of an Oxygen Clathrate Compound. Nature 1952, 170, 246-246.

(9) Ilczyszyn, M.; Selent, M.; Ilczyszyn, M. M. Participation of Xenon Guest in Hydrogen Bond Network of $\beta$-Hydroquinone Crystal. J. Phys. Chem. A 2012, 116, 3206-3214.

(10) Lee, Y.-J.; Han, K. W.; Jang, J. S.; Jeon, T.-I.; Park, J.; Kawamura, T.; Yamamoto, Y.; Sugahara, T.; Vogt, T.; Lee, J.-W.; Lee, Y.; Yoon, J.-H. Selective $\mathrm{CO}_{2}$ Trapping in Guest-Free Hydroquinone Clathrate Prepared by Gas Phase Synthesis. ChemPhysChem 2011, 12, $1056-1059$.

(11) Falenty, A.; Hansen, T. C.; Kuhs, W. F. Formation and Properties of Ice XVI Obtained by Emptying a Type sII Clathrate Hydrate. Nature 2014, 516, 231-233.

(12) Lee, J.-W.; Lee, Y.; Takeya, S.; Kawamura, T.; Yamamoto, Y.; Lee, Y.-J.; Yoon, J.-H. Gas-Phase Synthesis and Characterization of $\mathrm{CH}_{4}$-Loaded Hydroquinone Clathrates. J. Phys. Chem. B 2010, 114, 3254-3258

(13) Coupan, R.; Chabod, M.; Dicharry, C.; Diaz, J.; Miqueu, C.; Torré, J.-P. Experimental Determination of Phase Equilibria and Occupancies for $\mathrm{CO}_{2}, \mathrm{CH}_{4}$, and $\mathrm{N}_{2}$ Hydroquinone Clathrates. J. Chem. Eng. Data 2016, 61, 2565-2572.

(14) Coupan, R.; Péré, E.; Dicharry, C.; Plantier, F.; Diaz, J.; Khoukh, A.; Allouche, J.; Labat, S.; Pellerin, V.; Grenet, J.-P.; Sotiropoulos, J.-M.; Sénéchal, P.; Guerton, F.; Moonen, P.; Torré, J.P. A Characterization Study of $\mathrm{CO}_{2}, \mathrm{CH}_{4}$, and $\mathrm{CO}_{2} / \mathrm{CH}_{4}$ Hydroquinone Clathrates Formed by Gas-Solid Reaction. J. Phys. Chem. C 2017, 121, 22883-22894.

(15) Coupan, R.; Péré, E.; Dicharry, C.; Torré, J.-P. New Insights on Gas Hydroquinone Clathrates Using in Situ Raman Spectroscopy: Formation/Dissociation Mechanisms, Kinetics, and Capture Selectivity. J. Phys. Chem. A 2017, 121, 5450-5458.

(16) Coupan, R.; Torré, J.-P.; Dicharry, C.; Hemati, M.; Plantier, F. Kinetics of $\mathrm{CO}_{2}$ Capture by Hydroquinone Clathrates. Ind. Eng. Chem. Res. 2018, 57, 8172-8182.

(17) Coupan, R.; Plantier, F.; Torré, J.-P.; Dicharry, C.; Sénéchal, P.; Guerton, F.; Moonen, P.; Khoukh, A.; Kessas, S. A.; Hemati, M. Creating Innovative Composite Materials to Enhance the Kinetics of $\mathrm{CO}_{2}$ Capture by Hydroquinone Clathrates. Chem. Eng. J. 2017, 325, $35-48$.

(18) Torré, J.-P.; Coupan, R.; Chabod, M.; Péré, E.; Labat, S.; Khoukh, A.; Brown, R.; Sotiropoulos, J.-M.; Gornitzka, H. $\mathrm{CO}_{2}-$ Hydroquinone Clathrate: Synthesis, Purification, Characterization and Crystal Structure. Cryst. Growth Des. 2016, 16, 5330-5338.

(19) Health Council of the Netherlands. Hydroquinone and Benzoquinone. Health Based Recommended Occupational Exposure Limit; Health Council of the Netherlands: The Hague, The Netherlands, 2012; publication no. 2012/27.
(20) Brunauer, S.; Emmett, P. H.; Teller, E. Adsorption of Gases in Multimolecular Layers. J. Am. Chem. Soc. 1938, 60, 309-319.

(21) Barrett, E. P.; Joyner, L. G.; Halenda, P. P. The Determination of Pore Volume and Area Distributions in Porous Substances. I. Computations from Nitrogen Isotherms. J. Am. Chem. Soc. 1951, 73, $373-380$.

(22) Coupan, R.; Dicharry, C.; Torré, J.-P. Hydroquinone Clathrate Based Gas Separation (HCBGS): Application to the $\mathrm{CO}_{2} / \mathrm{CH}_{4}$ Gas Mixture. Fuel 2018, 226, 137-147.

(23) Pines, H.; Haag, W. O. Alumina: Catalyst and Support. I. Alumina, its Intrinsic Acidity and Catalytic Activity. J. Am. Chem. Soc. 1960, 82 (10), 2471-2483.

(24) de Barros Lima, I. P.; Lima, N. G. P. B.; Barros, D. M. C.; Oliveira, T. S.; Mendonca, C. M. S.; Barbosa, E. G.; Raffin, F. N.; Lima e Moura, T. F. A. d.; Gomes, A. P. B.; Ferrari, M.; Aragao, C. F. S. Compatibility Study between Hydroquinone and the Excipients Used in Semi-solid Pharmaceutical Forms by Thermal and Nonthermal Techniques. J. Therm. Anal. Calorim. 2015, 120, 719-732.

(25) McAdie, H. G. Thermal Decomposition of Molecular Complexes: IV. Further Studies of the [-quinol Clathrates. Can. J. Chem. 1966, 44, 1373-1386.

(26) Cuadrado-Collados, C.; Majid, A.; Martínez-Escandell, M.; Daemen, L.; Missyul, A.; Koh, C.; Silvestre-Albero, J. Freezing/ melting of Water in the Confined Nanospace of Carbon Materials: Effect of an External Stimulus. Carbon 2020, 158, 346-355.

(27) Radhakrishnan, R.; Gubbins, K. E.; Sliwinska-Bartkowiak, M. Effect of the Fluid-wall Interaction on Freezing of Confined Fluids: Toward the Development of a Global Phase Diagram. J. Chem. Phys. 2000, 112, 11048-11057.

(28) Kubinyi, M. J.; Keresztury, G. Infrared and Raman Spectra of Hydroquinone Crystalline Modifications. Mikrochim. Acta 1997, 14, 525-528.

(29) Heilala, B.; Makinen, A.; Nissinen, I.; Nissinen, J.; Makynen, A.; Peramaki, P. Evaluation of Time-gated Raman Spectroscopy for the Determination of Nitric, Sulfuric and Hydrofluoric Acid Concentrations in Pickle Liquor. Microchem. J. 2018, 137, 342-347.

(30) Akahama, Y.; Kawamura, H. Raman Spectroscopy on HighPressure Pluids of Molecular Oxygen and Nitrogen. Chem. Phys. Lett. 2004, 400, 326-330.

(31) Mak, T. C. W.; Tse, J. S.; Tse, C.-S.; Lee, K.-S.; Chong, Y.-H. Crystal Structure of a Clathrate inclusion Compound of Hydroquinone and Hydrogen Sulfide. J. Chem. Soc., Perkin Trans. 2 1976, 2, $1169-1172$.

(32) Ripmeester, J. A. Application of Solid State ${ }^{13} \mathrm{C}$ NMR to the Study of Polymorphs, Clathrates and Complexes. Chem. Phys. Lett. 1980, 74, 536-538.

(33) Lee, J.-W.; Choi, K. J.; Lee, Y.; Yoon, J.-H. Spectroscopic Identification and Conversion Rate of Gaseous Guest-Loaded Hydroquinone Clathrates. Chem. Phys. Lett. 2012, 528, 34-38.

(34) Mak, T. C.; Lam, C.-K. Encyclopedia of Supramolecular Chemistry; Atwood, J. L., Steed, J. W., Eds.; Marcel Dekker, 2004; pp 679-686.

(35) Conde, M. M.; Torré, J.-P.; Miqueu, C. Revisiting the Thermodynamic Modelling of Type I Gas-Hydroquinone Clathrates. Phys. Chem. Chem. Phys. 2016, 18, 10018-10027.

(36) Han, K. W.; Lee, Y.-J.; Jang, J. S.; Jeon, T.-I.; Park, J.; Kawamura, T.; Yamamoto, Y.; Sugahara, T.; Vogt, T.; Lee, J.-W.; Lee, Y.; Yoon, J.-H. Fast and Reversible Hydrogen Storage in Channel cages of Hydroquinone Clathrate. Chem. Phys. Lett. 2012, 546, 120124

(37) Torré, J.-P.; Gornitzka, H.; Coupan, R.; Dicharry, C.; PérezRodríguez, M.; Comesaña, A.; Piñeiro, M. M. Insights into the Crystal Structure and Clathration Selectivity of Organic Clathrates formed with Hydroquinone and $\left(\mathrm{CO}_{2}+\mathrm{CH}_{4}\right)$ Gas Mixtures. J. Phys. Chem. C 2019, 123, 14582-14590.

(38) Casco, M.; Silvestre-Albero, J.; Ramırez-Cuesta, A.; Rey, F.; Jorda, J.; Bansode, A.; Urakawa, A.; Peral, I.; Martınez-Escandell, M.; Kaneko, K.; Rodriguez-Reinoso, F. Methane Hydrate Formation in 
Confined Nanospace can surpass Nature. Nat. Commun. 2015, 6, 6432-6439.

(39) Casco, M.; Rey, F.; Jorda, J.; Rudic, S.; Fauth, F.; MartınezEscandell, M.; Rodriguez-Reinoso, F.; Ramos-Fernandez, E.; SilvestreAlbero, J. Paving the way for Methane Hydrate Formation on MetalOrganic Frameworks (MOFs). Chem. Sci. 2016, 7, 3658-3666.

(40) Linga, P.; Kumar, R.; Englezos, P. The Clathrate Hydrate Process for Post and Precombustion Capture of Carbon Dioxide. J. Hazard. Mater. 2007, 149, 625-629. 


\section{SUPPORTING INFORMATION}

\section{Novel Hydroquinone-Alumina Composites}

\section{Stabilizing a Guest-Free Clathrate Structure:}

\section{Applications in Gas Processing}

Romuald COUPAN ${ }^{1,2}$, Peter MOONEN ${ }^{1,3}$, Christophe DICHARRY ${ }^{1}$, Frédéric PLANTIER

4, Joseph DIAZ ', Eve PÉRÉ 5, Abdel KHOUKH 5, Fabrice GUERTON ${ }^{3}$, Pascale SÉNÉCHAL ${ }^{3}$, Cédric CHARVILLAT ${ }^{6}$, Marie-Line DE SOLAN 7 , Jean-Philippe TORRÉ $7^{*}$

1. Université de Pau et des Pays de l'Adour, E2S UPPA, CNRS, Total, LFCR, Pau, France

2. Total Research \& Technology Feluy, Zone Industrielle F eluy C, Seneffe, Belgium.

3. Université de Pau et des Pays de l'Adour, E2S UPPA, CNRS, DMEX, Pau, France

4. Université de Pau et des Pays de l'Adour, E2S UPPA, CNRS, Total, LFCR, Anglet, France

5. Université de Pau et des Pays de l'Adour, E2S UPPA, CNRS, IPREM, Pau, France.

6. CIRIMAT, Université de Toulouse, CNRS, INPT, UPS, Toulouse, France. 
7. Laboratoire de Génie Chimique, Université de Toulouse, CNRS, INPT, UPS, Toulouse, France.

\section{Corresponding Author}

* J ean-Philippe Torré. Laboratoire de Génie Chimique, Université de Toulouse, CNRS,

INPT, UPS, Toulouse, France. E-mail: jean-philippe.torre@ ensiacet.fr

\section{Characterization Apparatuses and Methods}

\section{Scanning Electron Microscopy (SEM)}

Benchtop scanning electron microscopy analyses are performed at $293 \mathrm{~K}$ in secondary vacuum conditions using a Hirox-SH300 microscope with an acceleration voltage of 20 kV. More in-depth electron microscopy analyses are performed by means of a field emission gun scanning electron microscope at $293 \mathrm{~K}$ and $10^{-5} \mathrm{~Pa}$ (secondary vacuum) using a J EOL J SM 7100F TTLS microscope. Both apparatus are equipped with an energy dispersive X-ray spectrometer. The samples are placed on double-sided adhesive carbon tape and metalized with gold coating. 


\section{Helium Pycnometry}

The particle density is measured using a Helium pycnometer Accupyc1330 from Micromeritics. Helium with a purity a $99.995 \%$ and a measurement cell of $1 \mathrm{~cm}^{3}$ are used for the analysis. 30 purges are done before density measurements, and the result obtained is the average of 10 measurements. The materials were dried during $24 \mathrm{hrs}$. at $50^{\circ} \mathrm{C}$ prior to analysis. For native alumina particles $(\mathrm{m}=0.6917 \mathrm{~g}, \mathrm{~T}=297.15 \mathrm{~K})$ : mean density $=3.0423 \pm 0.0020 \mathrm{~g} . \mathrm{cm}^{-3} ;$ for ground native alumina $(\mathrm{m}=0.6840 \mathrm{~g}, \mathrm{~T}=297.95$ K): mean density $=3.0426 \pm 0.0038 \mathrm{~g} \cdot \mathrm{cm}^{-3}$. The mean density value between native alumina particles and ground alumina: $3.0424 \pm 0.0030 \mathrm{~g} . \mathrm{cm}^{-3}$.

\section{X-ray Computed Tomography (XCT)}

X-ray computed tomography is performed using a Zeiss Xradia Versa 510T X-ray microscope with a resolution of $300 \mathrm{~nm} / \mathrm{voxel}$. Native alumina particle data are acquired using a tube voltage of $40 \mathrm{kV}$ at $3 \mathrm{~W}$, with an exposure time of $80 \mathrm{~s}$; the $3 \mathrm{D}$ dataset is obtained by reconstructing 1,201 independent radiographs. Impregnated alumina particle data are acquired using a tube voltage of $50 \mathrm{kV}$ at $4 \mathrm{~W}$, with an exposure time of $15 \mathrm{~s}$; 
this $3 D$ dataset is obtained by reconstructing 1,601 independent radiographs. Data are analyzed by means of Avizo 9 (Thermo Fisher Scientific), Fiji [J . Schindelin, I. ArgandaCarreras, E. Frise, et al., Fiji: an open-source platform for biological-image analysis, Nature methods 9 (2012) 676-682. doi:10.1038/nmeth.2019] and Matlab.

\section{Nitrogen adsorption-desorption tests}

Nitrogen adsorption-desorption tests (i.e. gas porosimetry) are done at $77 \mathrm{~K}$ using a fullyautomated Micromeritics TriStar II 3020 system. The samples are purified at $308 \mathrm{~K}$ and $10 \mathrm{~Pa}$ for 24 hours before the measurements are performed.

Thermogravimetric Analysis coupled with Differential Scanning Calorimetry (TGA/DSC)

Thermogravimetric analysis coupled with differential scanning calorimetry is performed using a Q 600 analyzer from TA Instruments by applying a heating ramp of $5 \mathrm{~K} / \mathrm{min}$ from ambient temperature to $773 \mathrm{~K}$ in an oxidizing atmosphere (air).

\section{Raman spectroscopy}


The Raman spectroscopy analyses are performed using a T-64000 Jobin-Yvon spectrometer fitted with a Raman notch filter, a 1,800 grooves/mm grating and a confocal microscope. The excitation source is the $514.5-\mathrm{nm}$ line of an argon ion laser. Each analysis is conducted in the $3,300-1,100 \mathrm{~cm}^{-1}$ region with an acquisition time of 60 seconds. The resolution is $\pm 2 \mathrm{~cm}^{-1}$.

\section{Nuclear Magnetic Resonance (NMR)}

Solid-state ${ }^{13} \mathrm{C}$ nuclear magnetic resonance is conducted at ambient temperature with a resonance frequency of $100.61 \mathrm{MHz}$ and a magic angle spinning rate of $7 \mathrm{kHz}$ using a Bruker Avance 400 spectrometer. The sample is placed in a zirconium rotor of $7 \mathrm{~mm}$. The contact time and pulse delay are $3.8 \mathrm{~ms}$ and $5 \mathrm{~s}$ respectively. Chemical shifts are referenced to tetramethylsilane at $0 \mathrm{ppm}$, and a glycine carbonyl signal of $176 \mathrm{ppm}$ serves as an external reference.

\section{Powder X-ray Diffraction (XRD) analysis}

XRD analyses were performed using a BRUKER D8 ADVANCE diffractometer. The X-rays were monochromatized to a wavelength of $1.5418 \AA$ using a parabolic mirror. Diagrams from the HQ 
samples were collected from 8.0 to 50.0 with a step size of $0.02^{\circ}$ and a step time of $1 \mathrm{~s}$. Lattice parameters were determined by Le Bail refinements of the XRD pattern, using the TOPAS software (BRUKER AXS). 